\title{
Repercusiones jurídico-políticas de la interdicción lingüística: tabú, censura y corrección política
}

\author{
Miguel Álvarez Ortega \\ Profesor doctor de Filosofía del Derecho \\ Universidad de Sevilla
}

Recibido: 26.11.2010

Aceptado: 20.12 .2010

\begin{abstract}
Resumen: El objeto del presente estudio se centra en realizar un acercamiento analítico a los tres principales mecanismos de interdicción sobre el lenguaje: el tabú, la censura y la corrección política, así como proporcionar un adecuado marco crítico. Para ello, se adopta una perspectiva histórica y lingüística en orden a establecer una explicación del origen y características de cada noción. Seguidamente, se analizan las consecuencias normativas de su dinámica social contemporánea, tratándose de establecer la relevancia jurídica y política de nociones normalmente relegadas al plano sociolingüístico. Se advierte de la necesidad de una mayor alerta académica y jurídico-política en torno a esta compleja red interdictiva, habida cuenta de su relevancia en la praxis del espacio público.

Palabras clave: tabú, corrección política, condicionantes sociolingüísticos del ordenamiento jurídico

Abstract: the aim of this paper is to develop an analytical approach to the three major current restrictions on speech: taboo, censorship and political correctness and to provide with a proper evaluation frame. An historical and linguistic angle is taken in order to provide a sound explanation of the origin and features of each notion. Then, the normative consequences of its current social dynamics is analysed trying to establish the legal and political relevance of notions usually regarded as merely socio-linguistic devices. Academic, legal and political concern is advised when addressing this complex web, considering the aforementioned legal and political relevance.
\end{abstract} system.

Key words: taboo, political correctness, sociolinguistic bindings of the legal

Sumario: 1. Introducción..-2. El tabú: la sombra de lo prohibido, innombrable y contaminante.-3. La censura: restricciones público-institucionales.-4. Higiene lingüística: la political correctness.-5. Mosaico interdictivo y espacio público.

\section{Introducción}

El 6 de mayo de 2008 apareció la necrológica de Mildred Loving, "una mujer negra que en los años cincuenta del pasado siglo se atrevió a romper el tabú del matrimonio entre blancos y negros en el Estado norteamericano 
de Virginia" . Al día siguiente, la prensa se hacía eco de la terrible catástrofe acaecida en Myanmar, país en el que "[1]a crisis económica -la inflación anual supera el 35\%- es un tema tabú para el Gobierno"2. Poco tiempo después, se publicaban las declaraciones del autor de la Historia de los maquis, David Baird, quien hacía alusión al hecho de que: "Durante años, (...) [había oído] anécdotas e historias sobre lo que pasó con la gente de la sierra. Nadie del pueblo quería hablar mucho. Había mucho miedo. Era un tema tabú"3.

Chen Kaige (Pekín, 1952), aclamado cineasta chino, con ocasión de una entrevista motivada por su primera incursión en el mundo de la ópera, anunciaba "que no contestar[ía] preguntas relacionadas con la censura en su país" ". Contemporáneamente, tenía lugar en nuestro espacio jurídico la inédita solicitud de medidas cautelares para la protección del derecho al honor, intimidad y la propia imagen por parte de Telma Ortiz, hermana de la Princesa de Asturias, ante el supuesto acoso de la prensa rosa. Los letrados de los periodistas venían a defender la improcedencia de tales medidas, calificadas de "censura previa".

Reflexionando sobre las acusaciones de racismo formuladas por la prensa inglesa contra el pueblo español, motivadas por ataques verbales producidos en campos de fútbol, el periodista John Carlin se expresó en los siguientes términos:

“es verdad, (...) que los ingleses, por más hooligans que sean, tienden a ser más políticamente correctos que los españoles; que demuestran más delicadeza con personas de otras razas. Es casi inimaginable hoy en día que en un campo de fútbol inglés se oiga a un aficionado imitando a un chimpancé al llegar el balón a los pies de un jugador negro ${ }^{6}$."

Por su parte, el dramaturgo catalán Albert Boadella, cuando acababa de estrenar su obra La cena, hacía gala de su habitual afición a la provocación al manifestar:

"A mí me gustan las cosas claras y en la dictadura lo estaban. Todos sabíamos a quien teníamos que odiar y a quien amar. Pero ahora, a pesar de la Constitución que nos protege, existen formas de

\footnotetext{
1 "Mildred Loving, activista contra la segregación racial en EEUU", en Necrológicas, El País, 06-05-2008.

2 "Un país en ruinas, pero rico en gas y opio", en Internacional, El País, 07-05-2008.

3 "Historia de una lucha sin cuartel", en Andalucía, El País, 09-05-2008

4 "Entrevista: Chen Kaige", en Comunidad Valenciana, El País, 10-05-2008

5 "Telma Ortiz critica el "insoportable y permanente acoso de la prensa", en Última hora. Gente, El País, 12-05-2008

6 "Lo políticamente correcto no aterriza", en Sociedad, El País, 09-04-2008
} 
marginación y censura que llevan a la muerte civil a los ciudadanos que no son políticamente correctos. Lo peor de todo es que este comportamiento parece lógico, cuando no lo es, porque esto es una democracia"7.

Estos fragmentos extractados de la prensa española permiten fácilmente constatar en qué medida el tabú, la censura y lo políticamente correcto forman parte habitual y cotidiana de nuestra realidad socio-lingüística y política. Pudiendo considerarse, grosso modo, como instrumentos diversos de prohibición sobre el uso del lenguaje, su presencia está lejos de responder a una nítida categorización que permita su ubicación en las sedes normativas y científicas correspondientes; a pesar de que cada figura cuenta con su propia decantación histórica y unidad de sentido. El presente trabajo se plantea como objetivo, por un lado, profundizar en sus ámbitos conceptuales y, por otro, observar su funcionamiento como mecanismos de ordenación social. Se pretende, así, llevar a cabo un acercamiento a los usos inderdictivos sobre el lenguaje como praxis socio-cultural contemporánea, con el objetivo último de avanzar en las repercusiones que desde el punto de vista de la ordenación del espacio público puedan tener tanto en sus solapamientos conceptuales como en sus auténticas incidencias jurídico-políticas.

\section{El tabú: la sombra de lo prohibido, innombrable y contaminante ${ }^{8}$}

El término tabú llegó al universo lingüístico occidental mediante la introducción efectuada por el Capitán James Cook en la lengua inglesa a finales del siglo XVIII. Cook escribió en su diario, al regresar de su tercer viaje a los Mares del Sur, que los nativos de Tonga hacían continua referencia al "tabú", que en general venía a significar que "una cosa está prohibida"":

"La palabra "tabú" (...) tiene una significación muy extendida. Los sacrificios humanos se denominan tangata tabú, y dicen también "tabú" de alguna cosa que esté prohibido comerla, o de la cual no hay que servirse. Nos dijeron que si el rey llegaba a entrar en casa de uno de sus súbditos, esta casa sería tabú y nunca más podría ser habitada por su propietario (...)"10.

7 "Entrevista: Albert Boadella, dramaturgo y director de Els Joglars", en Cultura, El País, 08-05-2008.

${ }^{8}$ Tomo la expresión de la obra de crítica cinematográfica y literaria: DomínGUEZ GARCíA, V., Tabú: la sombra de lo prohibido, innombrable y contaminante, Ocho y Medio: Festival Internacional de Cine de Gijón: Universidad de Oviedo, 2005.

${ }^{9}$ Cook, J., Tercer Viaje. Diarios de 1776 a 1780, trad. cast. de J. Pomar, José J. de Olañeta ed., Barcelona, 1982, p. 29, nota 6.

${ }^{10}$ Ibid., pp. 43-44. 
En 1888, el antropólogo James George Frazer, incluyó un artículo en la novena edición de la Encyclopaedia Britannica sobre el sistema del tabú, especialmente dedicado al ámbito polinesio. En la edición online de 2008, se recoge de esta forma:

"also spelled tabu, Tongan tabu, Maori tapu the prohibition of an action or the use of an object based on ritualistic distinctions of them either as being sacred and consecrated or as being dangerous, unclean, and accursed"11.

Tras las alusiones de Frazer, el estudio sobre La vida sexual de los salvajes del noroeste de Melanesia, publicado por Malinowski en $1932^{12}$, no sólo suscitaría el asombro y el escándalo de Occidente, sino que presentaría una interpretación diversa del problema del tabú, resucitado como nodo de interés para las Ciencias del Espíritu gracias a Sigmund Freud. En efecto, entre los años 1912 y 1913, Freud publicó una serie de artículos que luego serían recogidos en un libro titulado Tótem y tabú. Para el psicoanalista austriaco, "el tabú representa dos significaciones opuestas: la de lo sagrado o consagrado y la de lo inquietante, peligroso, prohibido o impuro" ${ }^{13}$. Su lectura del tabú como animadversión irracional que habría de poner en conexión a los pueblos primitivos con los enfermos de neurosis, enlazaba con la posición evolucionista de Frazer, y explica, asimismo, la aludida oposición de Malinowski, declarado anti-evolucionista. Pero, más que las divergencias interpretativas, interesa resaltar la existencia de una noción de corte antropológico y origen polinesio según la cual, puede entenderse que el tabú es una prohibición de origen trascendente (mágico-religioso) que implica la evitación de personas, objetos, lugares, palabras y acciones so pena de una contaminación transmisible que acarrea consecuencias negativas de índole diversa ${ }^{14}$. Más allá de esta definición mínima, se abriría un abanico de alter-

11 Encyclopaedia Britannica: http://www.britannica.com/eb/article-9070845/taboo. Nuestro DRAE consigna: “tabú. (Del polinesio tabú, lo prohibido).1. m. Condición de las personas, instituciones y cosas a las que no es lícito censurar o mencionar. 2. m. Prohibición de comer o tocar algún objeto, impuesta a sus adeptos por algunas religiones de la Polinesia". Diccionario de la Real Academia on line: http://buscon.rae.es/draeI/

${ }^{12}$ Malinowski, B., La vida sexual de los salvajes del noroeste de Melanesia, $2 .^{\circ}$ ed., trad. cast de R. Baeza, Ediciones Morata, Madrid, 1931.

${ }^{13}$ Freud, S., Tótem y tabú, 2. ${ }^{a}$ ed., trad. cast. de L. López Ballesteros y de Torres, Alianza, Madrid,1968, p. 29. Freud defiende que "Tabú es un palabra polinesia, cuya traducción se nos hace difícil porque no poseemos ya la noción correspondiente. Esta noción fue aún familiar a los romanos, cuyo sacer equivalía al tabú de los polinesios". Sobre la ambivalencia de la noción freudiana, vid. Levine, M. G., "The subject is Taboo", en $M L N$, vol. 101, n. ${ }^{\circ}$ 5, pp. 977-1002, 1986, pp. 977-1002.

${ }_{14}$ Cfr. Webster, H., Le tabou. Étude sociologique, trad. fr. de J. Marty, Payot, Paris, 1952, p. 6. 
nativas y variantes relativas a la duración, el mal ocasionado, la posibilidad y vías de purificación, el número y carácter de afectados o el origen personal (imposición explícita por parte de la autoridad) o impersonal (imposición implícita), entre otras características ${ }^{15}$.

Establecido este punto de partida, puede plantearse el traslado y aplicabilidad de la noción a la sede occidental y con especial referencia al ámbito lingüístico. A estos efectos, la existencia del lugar común del tabú de los cazadores como característica indoeuropea resulta de gran trascendencia ${ }^{16}$. En efecto, la prohibición de nombrar la pieza que se pretende cazar habría llegado incluso a nuestros días ${ }^{17}$. Y no sería la única. La inefabilidad del nombre de Dios, seña importantísima de la cultura lingüística judeo-cristiana $^{18}$, podría considerarse claro ejemplo de tabú lingüístico occidental, siendo productor fecundo de eufemismos desde la Antigüedad hasta el día de hoy. Una hipótesis explicativa generalizada asocia este tipo de prohibiciones con la perspectiva realista, de acuerdo con la cual, se produce una identificación entre el significante y el referente ${ }^{19}$. Nótese que aún hoy, el vocablo guaraní "Ñe' ê" significa tanto "palabra o lengua" como "alma"20. Resulta, además, significativa la defensa de que la misma "concepción trascendente de la palabra" le sea aplicable a los niños ${ }^{21}$ : se trata de la conexión entre lo primitivo y la debilidad mental, ya señalada por Freud.

A resultas de todo esto, podría sostenerse que el tabú lingüístico occidental es un subtipo del polinesio ratione materiae. Sin embargo, es difícil detectar la presencia de todos los elementos de la definición propuesta en los ejemplos que acaban de verse. Esto es especialmente cierto en lo que atañe

${ }^{15}$ Vid. ibid., pp. 15-51.

16 "El tabú lingüístico sobre animales de caza es (...) típico de comunidades de cazadores. El tabú venatorio parece debido principalmente a la primitiva creencia de que los animales entienden el lenguaje humano o incluso pueden hablarlo, de modo que pueden escapar del cazador o atacarlo por sorpresa si saben sus intenciones". "Oso, comadreja, lobo son, sobre todo en Eurasia, típicos animales totémicos y también por ello propicios al tabú". BAllester, X., "Indoeuropeo: una lengua para cazadores y recolectrices", Anuario Galego de filoloxia, n. ${ }^{\circ} 33,2006$, pp. 49-68 (cita, pp. 62-63).

${ }^{17}$ Casas Gómez, M., "El poder mágico de la palabra", Trivium, n. ${ }^{\circ} 8,1996$, pp. 29-52 (cit. en p. 43).

${ }^{18}$ Vid., in extenso, Graves, R., "El santo e inefable nombre de Dios", en La Diosa Blanca. Gramática histórica del mito poético, trad. cast. de L. Echávarri, Alianza, Madrid, 1994, pp. 360-399.

${ }^{19}$ Cfr. Casas Gómez, M., "El poder mágico de la palabra", Trivium, n. ${ }^{\circ} 8,1996$, pp 3039; CASAs Gómez, M., "Tabú de palabra e interdicción conceptual”, en A. PAMIES BerTrán, A. y LuQue DuRÁn, J. DE D. (eds.), Trabajos de lexicografía y fraseología contrastivas, Método Ediciones, Granada, 2000, pp. 84, 91.

${ }^{20}$ Delgado, S., "Poesía guaraní: la antigua búsqueda de la palabra-alma", Revista Electrónica: Documentos Lingüísticos y Literarios UACh, n. ${ }^{\circ}$ 29, 2006, www.humanidades. uach.cl/documentos_linguisticos/document.php?id=1236

${ }^{21}$ Casas Gómez, M., "El poder mágico de la palabra", Trivium, n. ${ }^{\circ}$ 8, 1996, pp. 36-37. 
al elemento "contaminante". La ruptura de un tabú implica la adquisición de una condición impura que resulta transmisible, lo que motiva la evitación por parte de la comunidad ${ }^{22}$. Parece complicado pensar que la misma dinámica se genere para el cazador que pronuncia el nombre de la pieza, pero así ocurría en ciertas islas polinesias cuando se pronunciaba el nombre del rey o de los miembros de su familia ${ }^{23}$. Es por ello que tal vez resulte útil acudir a una noción lingüística occidental del tabú, como la pergeñada por Casas Gómez:

"proceso por el cual determinadas palabras relacionadas con el ámbito mágico-religioso se eluden y se reemplazan por sustituciones eufemísticas en las que subyacen determinados mecanismos lingüísticos" 24 .

Se considera, así, que el tabú lingüístico es un subtipo del concepto más genérico de "interdicción lingüística":

"presión externa, psicológica o social que motiva la no utilización de ciertas formas léxicas existentes en la lengua, originando el proceso eufemístico" ${ }^{25}$;

debiendo tenerse presente que "en al ámbito interdictivo no todo es sustitución léxica" (cabría, siguiendo a J. Uría Varela, la modulación mediante fórmulas de excusa o mecanismos basados en el tono de voz, la entonación o la gestualidad ${ }^{26}$ ), "lo que permite enfocar el proceso no tanto desde el término interdicto sino desde un "contenido" o realidad interdicta" 27.

Pero aún existe otro problema terminológico en este ámbito del que se hace eco el propio Casas Gómez ${ }^{28}$. Y es que el tratamiento del tabú lingüístico contemporáneo por parte de la bibliografía actual está lejos de respetar

${ }^{22}$ Aún así, para un acercamiento que pone el énfasis en la noción de contaminación, suciedad e impureza como signos que persisten hoy día en el tabú como expresión del caos frente al orden social, vid. Douglas, M., Purity and Danger. An analysis of the concepts of pollution and taboo, Routledge and Kegan Paul, London, Boston and Henley, 1980.

${ }^{23}$ Webster, H., Le tabou. Étude sociologique, trad. fr. de J. Marty, Payot, Paris, 1952, p. 16.

${ }^{24}$ Casas Gómez, M., "El poder mágico de la palabra”, Trivium, n. ${ }^{\circ}$ 8, 1996, p. 38.

${ }^{25}$ Ibidem.

${ }^{26}$ Uría Varela, J., Tabú y eufemismo en latín, Hakkert, Amsterdam, 1997, p. 6, cit. por CAsas Gómez, M., "Tabú de palabra e interdicción conceptual”, en A. PAmies Bertrán, A. y LuQue DurÁN, J. DE D. (eds.), Trabajos de lexicografía y fraseología contrastivas, Método Ediciones, Granada, 2000, pp. 88-89.

${ }^{27}$ Ibid., p. 89.

${ }^{28}$ CASAs Gómez, M., "Tabú de palabra e interdicción conceptual”, en A. PAMIES BerTRÁn, A. y LuQue DurÁn, J. DE D. (eds.), Trabajos de lexicografía y fraseología contrastivas, Método Ediciones, Granada, 2000, pp. 79-98. (cit. en p. 84). 
este tipo de distinciones conceptuales y es habitual que toda proscripción léxica sea considerada como tabú, con independencia de su ámbito material o su motivación ${ }^{29}$. Ello no facilita, precisamente, un uso técnicamente depurado por parte del lego.

De todo ello parece poder inferirse, brevemente, que cohabitan hoy día al menos tres nociones diversas para el tabú lingüístico: 1) la noción polinesia originaria, de prohibición de origen trascendente (mágico-religioso) que implica la evitación de palabras so pena de una contaminación transmisible que acarrea consecuencias negativas de índole diversa; 2) la occidental estricta, de elisión léxica por motivación mágico-religiosa (identificándose principalmente con la perspectiva realista); 3) la occidental genérica, que recoge la prohibición léxica con independencia de su ámbito material y/o motivacional.

\section{La censura: restricciones público-institucionales}

El término censura sí que cuenta con una antigua raigambre románica. Censura es un derivado del verbo latino "censeo", significando, en el mayor número de sus acepciones, pensamiento, expresión de una opinión o valoración $^{30}$. Tal núcleo semántico ha sido el prevalente hasta tiempos muy recien-

${ }^{29}$ El acercamiento sociolingüístico variacionista de López Morales, las reflexiones sobre tabú y censura lingüística de Chamizo Domínguez o el interesante estudio de Haas sobre los tabúes interlingüísticos, por tomar algunos ejemplos, parten todos de una noción mucho más amplia. Las "four-letter" words de la lengua inglesa, determinadas expresiones de la cópula y la genitalidad humanas, o incluso la evitación de la palabra "pequeño" en las porciones de los menús de los restaurantes, difícilmente pueden ser reconducidas a la noción de Casas Gómez del tabú como interdicción lingüística de carácter mágico-religioso. Por supuesto, menos aún, a la importada en su día por James Cook. Vid. LóPEZ MoRALES, H.,"Sociolingüística del tabú”, Interlingüística, n. ${ }^{\circ} 16$, (Ejemplar dedicado a: XX Encuentro de la Asociación de Jóvenes Lingüistas), 2005, www.usal.es/gabinete/comunicacion/conferencia_ humberto.pdf; CHAMizo Domínguez, P. J., "Tabú y lenguaje: las palabras vitandas y la censura lingüística", Thémata. Revista de Filosofía, n. ${ }^{\circ}$ 40, 2008, pp. 31-46; HaAs, M. R., "Interlingual Word Taboos", American Anthropologist, vol. 53, n. ${ }^{\circ} 3$, 1951, pp. 338-344. "Some years ago, a Creek Indian informant in Oklahoma stated that the Indians tended to avoid the use of certain words of their own language when white people were around. It turned out that the avoided words were those which bear some phonetic similarity to the "fourletter" words of English". "A few years later it became apparent that Thai students studying in this country also tend to avoid certain words of their own language which bear a phonetic resemblance to English obscene words" (338). "In general it is the speakers of the minority language who feel obliged to observe the taboo, which, though the result of contact, is not actually imposed by the speakers of the majority language; for the latter in their ignorance of the minority language (except when proper names are involved), are normally quite unaware of the problem" (344).

${ }^{30}$ Vid. Oxford Latin Dictionary, ed. a cargo de P. G. W. Glare, Clarendon Press, Oxford, 2006, pp. 297-298; Nuevo Diccionario Etimológico Latín- Español y de las voces derivadas, Universidad de Deusto, Bilbao, 2003, p. 110. 
tes. Valga de botón de muestra la obra de Simon van Leeuwen, práctico neerlandés del siglo XVII, aparecida como Censura forensis theoretico-practica, id est iuris civilis Romani usuque recepti \& practici methodica collatio $(\ldots)^{31}$, y en la que "censura" está desprovista de todo significado negativo de restricción de la expresión. Tal significado -la censura como restricción u opresión ejercida sobre determinada unidad de pensamiento- se deriva de su acepción en calidad de valoración o juicio aplicado especialmente a las obras escritas $^{32}$. Ahora bien, tal decantación de significado es posterior a la existencia de la actividad, es decir, el ejercicio de lo que hoy llamamos censura es bastante anterior al alumbramiento de un término específico para la misma o, mejor dicho, de la consolidación de la acepción para el significante "censura".

Así, de acuerdo con Jesús Gil, la censura occidental nace en la época griega pre-clásica con Zaleuco, quien estableció la primera regulación de la maledicencia pública (S. VII a.C.) ${ }^{33}$. El primer ejemplo de censura literaria se debería a la supresión de competiciones de rapsodas homéricos en la ciudad de Sición. Atenas habría de ser considerada la ciudad "donde por primera vez se realizaron intentos serios de poner cortapisas legales a la libertad de palabra y de magisterio" 34 . Una de las primeras figuras en ser objeto de persecución por sus ideas fue el filósofo Protágoras, pues a raíz de una lectura pública de su tratado Sobre los dioses, en el que expresaba un declarado agnosticismo, se quemaron en el ágora todos sus libros y los ejemplares en manos de particulares fueron requisados ${ }^{35}$. De acuerdo, pues, con Gil, "ninguno de cuantos escribieron o enseñaron a finales del siglo $\mathrm{V}$ en Atenas

${ }^{31}$ El título completo sería: LeEuwen S. V. (1685): Censura forensis theoretico-practica id est totius juris civilis, Romani, Usuque recepti, \& Practici methodica collatio Qua non tantum ipsa Juris Romani fundamenta, ad rationis, \& veritatis censuram, Methodice reducuntur; sed \& ad usum practicum transferuntur, interjectis Constitutionibus, Decisionibus, Moribus, \& statutis, non tantum generalioribus, verum etiam particularibus cujusque fere Christianorum gentis, Regionis, \& Provinciae. Editio tertia Altera auctior.

32 "censura. (Del lat. cens? ra). 1. f. Dictamen y juicio que se hace o da acerca de una obra o escrito.2. f. Nota, corrección o reprobación de algo.3. f. Murmuración, detracción.4. f. Intervención que ejerce el censor gubernativo.5. f. Pena eclesiástica del fuero externo, impuesta por algún delito con arreglo a los cánones.6. f. Entre los antiguos romanos, oficio y dignidad de censor.7. f. Psicol. Vigilancia que ejercen el yo y el superyó sobre el ello, para impedir el acceso a la conciencia de impulsos nocivos para el equilibrio psíquico.8. f. ant. Padrón, asiento, registro o matrícula". Diccionario de la Real Academia on line: http://buscon.rae.es/draeI/

33 "Que nadie hable mal, ni de la ciudad como comunidad, ni de ciudadano alguno como particular, y que los vigilantes de las leyes se encarguen de reprender a quienes infrinjan este precepto, primero amonestándolos, luego imponiéndoles una multa”. GIL, J., La censura en el mundo antiguo, 2. ${ }^{\mathrm{a}}$ ed., Alianza, Madrid, 1985, p.33.

${ }^{34}$ Ibid., pp. 36-37, 50.

${ }^{35}$ Ibid, p. 57. 
se atrevió a emitir con sinceridad el juicio que le merecían los dioses de la tradición" 36 .

Lo que en Grecia fueron señales y atisbos dispersos, habría de reafirmarse y perfeccionarse desde el punto de vista técnico-jurídico en Roma, que ya contaba en su ley de las XII Tablas con una mención explícita de la difamación $^{37}$. La lex Cornelia de iniuriis y la iniuriarium actio surgieron para la protección del honor de los particulares y perseguir judicialmente al autor de libelo difamatorio ${ }^{38}$. Y, en general, la regulación se acentuaría en el Bajo Imperio, especialmente mediante los edictos de los emperadores cristianos y el Decretum Gelasianum ${ }^{39}$.

No parece arriesgado afirmar que, desde Roma, la censura pasa a ser una función más de las potestades político-institucionales. La entrada en juego del poder eclesiástico no supone sino el reforzamiento -que no la aparición, como se ha tenido ocasión de ver- de los motivos religiosos para la censura, a la par que un importante desarrollo del derecho y las instancias canónicas dedicadas a tales menesteres: las listas de libros prohibidos resultan un "clásico" en este ámbito. No será hasta la entrada en escena de los modelos doctrinales de Locke y Kant cuando comience a oponerse a la normalidad de la censura lo que hoy día denominamos como "derecho a la libertad de expresión" ${ }^{40}$. Una vez que se gesta el modelo liberal, según el cual el Estado debe garantizar espacios de no injerencia respecto al individuo, se pone en cuestionamiento la legitimidad de medidas que cercenan el soporte básico del libre desarrollo de la persona, así como la formación de la opinión pública, pilar de la democracia ${ }^{41}$. Ello no quiere decir, sea como fuere, que movimientos como el revolucionario francés fueran ajenos a la censura ${ }^{42}$.

En la actualidad, los catálogos de derechos fundamentales de las constituciones han ido consagrando, especialmente tras las Segunda Guerra Mundial, la libertad de expresión, aunque con diverso alcance y protección técni-

${ }^{36}$ Ibid., pp. 59-60.

37 "Actualmente, pues, parece haber quedado firmemente establecido que la la ley de las XII Tablas contaba con un artículo relativo a la difamación de palabra, susceptible de hacerse extensivo a la difamación por escrito, en el momento en que el hábito de lectura se difundiese en la sociedad, y por ende, con la potencialidad de emplearse con fines censoriales en la literatura". Ibid., p. 115.

${ }^{38}$ Ibid., p. 118.

${ }^{39}$ Ibid., pp. 197ss, 247, ss, 314.

${ }^{40}$ Ansuátegui Roig, F. C., Orígenes doctrinales de la libertad de expresión, Universidad Carlos III de Madrid. BOE, Madrid, 1994, esp. pp. 264 ss, 438 ss.

${ }^{41}$ Cfr. SÁnchez GonzÁLez, S. "Libertad de expresión y democracia", en La libertad de expresión, Marcial Pons, Madrid, 1992, pp. 53-104.

${ }^{42}$ Una interesante comparación entre la censura de la Francia del XVIII y la de la Alemania del Este al final del régimen comunista puede hallarse en DARNTON, R.,"Censorship, a comparative view: France, 1789 - East Germany, 1989”, Representations, n. ${ }^{\circ} 49,1995$, pp. 40-60. 
$\mathrm{ca}^{43}$. Para el caso español, el sistema actual es resultado de la recuperación democrática tras la dictadura franquista ${ }^{44}$. Así, el art. $20 \mathrm{CE}$ viene a recoger la libertad de expresión del pensamiento, la creación artística y científica, la libertad de cátedra y de comunicación; sin que tales derechos puedan "restringirse mediante ningún tipo de censura previa".

Debe tenerse presente que, como en el resto de Estados modernos, se trata de una libertad limitada, señaladamente, por el propio sistema de derechos fundamentales. De acuerdo con la doctrina constitucionalista, los límites a la libertad de expresión son: 1) por razón del sujeto, la protección de la juventud y la infancia, el deber de secreto del trabajador y las limitaciones de los funcionarios públicos; y 2), por razón del objeto, el derecho al honor, la intimidad y la propia imagen, la exigencia de veracidad, la moral y el orden público ${ }^{45}$.

Como se ha señalado, la única referencia expresa a la censura en nuestro texto constitucional se halla en el 20.2 ("El ejercicio de estos derechos no puede restringirse mediante ningún tipo de censura previa"). Nuestro Tribunal Constitucional entiende que el texto alude a

"cualquier medida limitadora de la elaboración o difusión de una obra del espíritu, especialmente al hacerla depender de un examen previo oficial de su contenido. Dicho examen implica la finalidad de enjuiciar la obra en cuestión con arreglo a unos valores abstractos y

${ }^{43}$ De acuerdo con el estudio comparatista de Villanueva, pueden distinguirse los siguientes modelos en el mundo: 1) países que no recogen previsiones constitucionales en torno a las libertades de expresión e información (4 \% de los países, entre ellos, Gran Bretaña); 2) países con sistema improtectivo, que no reconocen estas libertades a nivel constitucional o delega su establecimiento a la ley; 7\%); 3) sistema decimonónico, según el cual el deber de abstención del Estado se fija a nivel constitucional (48 \%); 4) sistema minimalista, que también reconoce la libertad de expresión e imprenta y la libertad de información (25\%); 5) sistema cuasi-paradigmático, en el que se introduce también el derecho de réplica, el acceso a documentos públicos y la cláusula de conciencia del periodista $(9 \%)$ y 6), el más completo, que es el paradigmático (7\%, incluyendo España). Villanueva, E., Régimen Constitucional de las Libertades de Expresión e Información en los Países del Mundo, fragua editorial, Madrid, 1997., pp. 27-29.

${ }^{44}$ Vid. Gubern, R., La censura. Función política y ordenamiento jurídico bajo el franquismo (1936-1975), E. P., Barcelona, 1981.

${ }^{45}$ CREmades, J., Los límites de la libertad de expresión en el ordenamiento jurídico español, La ley-actualidad, Las Rozas, 1995, pp. 149-167, 173-276. De acuerdo con Catalá i Bas, la recepción jurídico-constitucional española de la jurisprudencia de Estrasburgo, permitiría la siguiente clasificación: intereses generales (seguridad nacional, integridad territorial, la defensa del orden y la prevención del delito, el secreto de sumario, los valores democráticos) y derechos ajenos (vida privada, honor o reputación ajena, derecho a la propia imagen, derecho a un proceso justo, derecho a unas elecciones libres). CATALÁ i BAS, A. H., Libertad de expresión e información. La jurisprudencia del TEDH y su recepción por el Tribunal Constitucional, ediciones Revista general de derecho, Valencia, 2001, pp. 299-405. 
restrictivos de la libertad, de tal manera que se otorgue el placet $\mathrm{o}$ visto bueno a la publicación o difusión de la obra que se acomode a ellos a juicio del censor, y se le niegue cuando no sea así" 46 .

Vista esta breve panorámica sobre la evolución histórica de la censura como medida público-institucional restrictiva, es preciso recodar que, tal y como se ha visto que recoge el DRAE, existen diversas sedes desde las que puede ejercerse la restricción. Se habla de censura política, social, cultural e, incluso, de autocensura. En todos estos casos, se mantiene el continuum de limitación sobre la emisión y recepción de mensajes por parte de los hablantes. De nuevo, como en el caso del tabú, la pluralidad de nociones viene a requerir una serie de puntualizaciones clarificadoras que sirvan, a su vez, de conclusiones parciales y provisionales.

Puede así sostenerse que: 1) las restricciones público-institucionales sobre la comunicación humana pueden remontarse al pasado greco-latino; 2) la inclusión de tal acepción para el significante "censura" es posterior al ejercicio de tal actividad; 3 ) a la normalidad de la función estatal de la censura, la consolidación de las democracias occidentales opone el derecho a la libertad de expresión, derecho que no se presenta con carácter absoluto e ilimitado; 4) ello implica la posibilidad constitucional de limitaciones de la libertad de expresión, excluyendo la censura previa; 5) el uso no técnico del término "censura" supone una ampliación de su ámbito objetivo y subjetivo a una gran pluralidad de manifestaciones de la restricción de la comunicación humana.

\section{Higiene lingüística: la political correctness}

La más reciente forma de interdicción lingüística es lo que se ha venido a denominar "lo políticamente correcto", compuesto español que resulta de un calco del inglés "political correctness" (PC). Las primeras noticias de uso de la expresión se remontan a la resolución de la Corte Suprema Americana en el caso Chisholm v. Georgia en $1793^{47}$. Pero no sería hasta finales de los sesenta, principios de los setenta del siglo veinte, cuando se recupere, comenzando a adquirir el sentido que se le otorga en la actualidad. Al parecer, fueron los grupos de izquierda estadounidenses quienes tomaron la expresión, bien de la traducción inglesa del Libro Rojo de Mao o de la línea ideológica marcada por el Partido Comunista ${ }^{48}$. Según J. K. Wilson, quien

\footnotetext{
${ }^{46}$ CREmades, J., Los límites de la libertad de expresión en el ordenamiento jurídico espanol, La ley-actualidad, Las Rozas, 1995, pp. 105-106.

${ }^{47}$ WILson, J. K, The Myth of Political Correctness. The Conservative Attack on Higher Education, Duke University Press, Durham and London, 1995, p. 3.

${ }^{48}$ CAMERON, D. (1994): “"Words, words, words”: the power of language”, en Dunant, S. (Ed.), The War of the Words. The Political Correctness Debate, Virago press, London, pp. 18-19.
} 
sigue a Roger Geiger, la PC surgió como una "sarcastic reference to adherence to the party line by American communists in the 1930s"49. D. Cameron, en la misma línea, alude a que el uso originario era, más bien, de autocrítica irónica $^{50}$. S. Hall lo narra de la siguiente manera:

"According to one version, political correctness actually began as an in-joke on the left: radical students on American campuses acting out an ironic replay of the Bad Old Days BS (Before the Sixties) when every revolutionary groupuscule had a party line about everything. They would address some glaring example of sexist or racist behavior by their fellow students in imitation of the tone of voice of the Red Guards or Cultural Revolution Commissar: "Not very politically correct", Comrade!"51

Lo que se señala que comenzó a modo de irónica autocrítica, acabaría por consolidarse como una praxis universitaria y, posteriormente pública, en los años ochenta, afectando a la vida en los campus universitarios, a los autores y materias académicas (evitación del canon occidental identificado con los denominados "dead white european males"), la protección de las minorías y el lenguaje empleado en los medios de comunicación ${ }^{52}$. Así, la creación de cuotas para minorías étnicas, la inclusión de autores asiáticos u homosexuales en los temarios, o referirse a los negros como "afro-americanos", pasó a ser considerado políticamente correcto.

Este "movimiento", por así decirlo, no tardaría en recibir duras críticas por parte de los liberales y conservadores. En 1991, el presidente Bush se dirigía a la comunidad universitaria de Michigan defendiendo ardientemente la libertad de expresión frente al nuevo Macartismo de la PC ${ }^{53}$. Los detractores aludían a que la obsesión por la "higiene verbal" acababa por pervertir innecesariamente el lenguaje o, de forma más contundente, que dirigía la

\footnotetext{
${ }^{49}$ WiLson, J. K, The Myth of Political Correctness. The Conservative Attack on Higher Education, Duke University Press, Durham and London, 1995, p. 4.

50 "The most common use of "politically correct" was ironic - to quote Maurice Isserman, writing in the progressive Jewish magazine Tikkun in 1991, "it was always used in a tone mocking the pieties of our own insular political counterculture, as in "we could stop at McDonald's down the road if you're hungry...but it wouldn't be politically correct"". CAmeron, D., ““'Words, words, words”: the power of language”, en DunAnT, S. (Ed.), The War of the Words. The Political Correctness Debate, Virago press, London, 1994, p 19.

${ }^{51}$ Hall, S. "Some "politically incorrect" pathways through PC", en DunANT, S. (Ed.), The War of the Words. The Political Correctness Debate, Virago press, London, 1994, pp.164-165.

${ }^{52}$ Gomis Van Heteren, A., Political correctness in context (The PC Controversy in America), Universidad de Almería, 1997, pp. 49ss, 83 ss, 115ss, 113ss, 137ss.

${ }^{53}$ Annette, J.,"The culture wars on the American campus", en DunAnt, S. (Ed.), The War of the Words. The Political Correctness Debate, Virago press, London, 1994, p. 2.
} 
acción política hacia los usos del lenguaje en lugar de a la transformación de la realidad. En el trasfondo flotaría la idea, insinuada por Bush, de hallarnos realmente ante un atentado a la libertad de expresión ${ }^{54}$. Con independencia de la plausibilidad de estas críticas, es necesario advertir que el propio fenómeno es magnificado por sus atacantes, pues los pretendidos condicionantes de la PC respecto a la vida académica son mucho menos cuantiosos y significativos de lo que las reacciones pretenden ${ }^{55}$. A esto deben añadirse las connotaciones ambivalentes que ha llegado a adquirir el término, tanto en sectores de izquierdas como de derechas, en los que puede llegar a vender mucho más la etiqueta de lo políticamente incorrecto. En efecto, al halo acrítico, conformista e incluso insustancial, por formalista, de lo políticamente correcto, se opone la valentía, sinceridad y sustancialidad de lo incorrecto, de quien se atreve a expresarse aún a riesgo de ir contra corriente.

Desde un punto de vista más estrictamente lingüístico, cabe señalar la asociación de la PC con la producción de eufemismos y el uso del denominado lenguaje inclusivo. Dado que determinadas unidades deben ser evitadas por contrariar el ideario básico progresista, los hablantes se ven constreñidos a emplear eufemismos, que vienen, a veces, directamente impuestos por la propia línea de corrección. De esta forma, la PC no sólo dicta lo que debe ser evitado, sino lo que debe ser empleado en su lugar para promover la igualdad y la tolerancia ${ }^{56}$.

Realizado este bosquejo, toca precisar en qué consiste la PC como vía de interdicción lingüística. A este respecto, debe indicarse que, al contrario de lo visto en los casos anteriores, el DRAE no recoge ninguna definición. El Merriam-Webster Dictionary de la lengua inglesa, en cambio, posee una entrada para "politically correct":

"conforming to a belief that language and practices which could offend political sensibilities (as in matters of sex or race) should be eliminated"57.

De acuerdo con el recorrido realizado, parece poder deducirse que la PC es un mecanismo de interdicción lingüística que, so pretexto de acomoda-

${ }^{54}$ Dunant, S. (Ed.), The War of the Words. The Political Correctness Debate, Virago press, London, 1994, pp. 22-23.

${ }^{55}$ Esa es la tesis central que recorre la obra: Wilson, J. K, The Myth of Political Correctness. The Conservative Attack on Higher Education, Duke University Press, Durham and London, 1995; vid. también ANNETTE, J. "The culture wars on the American campus", en Dunant, S. (Ed.), The War of the Words. The Political Correctness Debate, Virago press, London, 1994, p. 9.

${ }^{56}$ Vid. Gomis Van Heteren, A., Political correctness in context (The PC Controversy in America), Universidad de Almería, 1997, pp. 25-26

${ }^{57}$ Merriam-Webster Dictionary: http://www.merriam-webster.com /dictionary/ political\%20 correctness 
ción a una ideología progresista y centrada en la visibilización de las minorías en el espacio público, así como en la remoción de afrentas históricas, impone la evitación de unidades pretendidamente portadoras de connotaciones discriminadoras a favor de otras pretendidamente neutras e integradoras.

\section{Mosaico interdictivo y espacio público}

El ejercicio realizado hasta ahora bien podría considerarse un mero divertimento analítico que, entre otras cosas, no reflejaría fielmente los usos asentados sobre las unidades analizadas. Así, la difusión y notas comunes que presentan el tabú, la censura y la corrección política en tanto que formas de interdicción sobre el lenguaje, provocan la existencia de una pluralidad de acepciones a resultas de la cual, el alejarse mínimamente de las nociones más estrictas y técnicas desemboca en confusiones y solapamientos. Así, expresiones del tipo: “"'negro" es una palabra tabú hoy día”; "mi padre me censura cuando digo palabrotas"; o "pronunciar el nombre de Dios no es políticamente correcto", no resultan extrañas para un hablante castellano. Sin embargo, de acuerdo con las delimitaciones técnicas que se han tratado de llevar a cabo, tales expresiones serían bastante imprecisas, ya que "negro" no se evita por motivaciones mágico-religiosas; un padre no ejerce potestades público-institucionales frente a un hijo y los nombres de la divinidad no forman parte del conjunto de unidades que la pretendida izquierda tolerante quiere evitar.

El mantenimiento del celo terminológico en este ámbito podría, además, considerarse exclusivamente preocupación propia de humanistas y científicos sociales en el desarrollo de sus respectivos campos de estudio. Ahora bien, no debe perderse de vista que el tratamiento de nociones interdictivas debe ser objeto de interés desde una perspectiva normativa de conformación del espacio público. Es decir, el tratarse de un problema prescriptivo debería prima facie atraer la atención de filósofos de la moral, juristas y politólogos. Un planteamiento de feliz y límpida disección se vería tentado de considerar el tabú como problema sociológico o moral; la censura como cuestión jurídica y la corrección política como preocupación socio-política ${ }^{58}$. Tal esquema, además, podría entender que el más grave y eficaz instrumento sería el de naturaleza jurídica, pues pertenece al ámbito normativo básico habilitan-

\footnotetext{
${ }^{58}$ Tal planteamiento halla plausibilidad además en la distinción de las características sancionatorias. En el caso del tabú, existe una motivación mágico-religiosa y la sanción dependerá de si se trata del término polinesio (contaminación), del actual estricto (fuerte reprobación social) o del actual amplio (reprobación social graduable). La censura tiene justificación en los intereses y la moralidad de la res publica y sus sanciones implican la puesta en marcha del aparato estatal. Y la PC se motiva por los valores de un supuesto ideario progresista, consistiendo sus sanciones en repulsa privada o castigo político, según el ámbito de que se trate.
} 
te de la convivencia. No obstante, los propios solapamientos y reenvíos mencionados en el acercamiento terminológico ponen en la pista de que las dinámicas normativas presentan una complejidad escasamente compatible con la Reinheit disciplinar soñada por los juristas positivistas. El pensar, además, que las sanciones sociales son menos graves o eficaces que las jurídicas parecería incurrir en una cierta ingenuidad en el panorama iusteórico actual.

Se precisa, pues, indagar en la naturaleza dinámica e inter-normativa que presentan los instrumentos estudiados. La incidencia de la esfera jurídicoformal en la socio-política es la más fácilmente detectable por el obvio formalismo promulgatorio. Resulta, al mismo tiempo, la más garantista, pues sus instrumentos se articulan a modo de excepción constitucionalmente justificable de la libertad de expresión. Mayor complejidad e interés reviste transitar el camino en sentido contrario y observar los condicionantes sociolingüísticos de la realidad jurídico-política.

Aquí, el panorama nacional proporciona no pocos ejemplos de la relevancia institucional de los mecanismos de interdicción lingüística. No sólo puede constatarse la naturaleza más primitiva del tabú cuando se insiste hasta la saciedad en hablar de "desaceleración económica" por temor a que la pronunciación de la palabra "crisis" se convierta literalmente en una invocación y la crisis se haga cuerpo ${ }^{59}$; sino que la sustitución eufemística es refuerzo impagable cuando se quieren evitar determinados efectos jurídico-políticos: baste de ejemplo la alusión a la "participación de las fuerzas armadas para apoyo humanitario en la crisis de Irak"60, buscándose prescindir del

59 Aunque desde cierta posición técnico-económica pudiese tratar de justificarse el empleo de "desaceleración", entendida como "proceso de disminución transitorio del ritmo de crecimiento" [vid. e.g., http://asgconsultores.com/diccionario/letra/d.htm], parece razonable entender que la evitación de la palabra "crisis" tenía como principal motivación no sólo eludir una mala imagen del gobierno, sino evitar las reacciones de los actores económicos en un cierto sentido que no haría sino agravar la situación, es decir, materializar de forma más patente la esquiva "crisis". "Debilidades" ["Ni crisis, ni desaceleración: Zapatero habla ahora de "debilidades" económicas", en El Confidencial.com, Viernes, 25 de julio de 2008] o "dificultades serias" ["Zapatero admite por primera vez que la economía tiene “dificultades serias"”, en Cotizalia, Martes, 24 de junio de 2008] fueron otros eufemismos empleados por el Presidente del Gobierno antes de admitir finalmente la realidad de la "crisis" en una entrevista televisiva realizada el 07/07/08. Al día siguiente, el diario El País recogía: “Estamos en crisis? La palabra tabú para el presidente del Gobierno, José Luis Rodríguez Zapatero, ha sido la primera cuestión que ha tenido que responder esta noche en una entrevista en televisión". "Zapatero menciona por primera vez la palabra crisis para referirse a la situación económica", en El País, 08/07/2008.

${ }^{60}$ Expresión por la que es optó en el Acuerdo del Consejo de Ministros de 21 de Marzo de 2003. Para un estudio comprehensivo del lenguaje político español contemporáneo y las constricciones de la corrección política, puede consultarse: GUITART EsCUDERO, M. P., Lenguaje político y lenguaje políticamente correcto en España (con especial atención al discurso parlamentario), Tesis doctoral, Universitat de Valencia, Servei de Publicacions, 2005, disponible online en: http://www.tesisenxarxa.net/TDX-0628106-110835/. 
apoyo parlamentario evitando expresiones como "conflicto armado" o, la más temida, "guerra" 61 .

Las repercusiones de las sustituciones eufemísticas pueden sentirse igualmente en otros niveles más sutiles. El tránsito bienintencionado desde "preso" y "cárcel" a "interno" y "establecimiento penitenciario"; o desde "subnormal" a "minusválido o discapacitado psíquico"62 o "persona con necesidades especiales", no sólo se basa en un intento de redignificación sociolingüística de sujetos que se hallan en determinada situación o poseen determinadas características, sino que supone que los operadores jurídicos razonan partiendo de una unidad lingüística distinta, con un horizonte normativo y teleológico distinto; pues, como señalaba Casas Gómez, más que ante términos interdictos, estamos ante un "contenido" o realidad interdic$\mathrm{ta}^{63}$. A un preso se le supone en una situación por naturaleza restrictiva con respecto a sus derechos y alguien que presenta características intelectuales y cognitivas muy inferiores a la media se sitúa en clara asimetría en términos de mérito y capacidad (que no, obviamente, de dignidad). Sus sustitutos eufemísticos crean un espejismo de simetría que puede llevar a reivindicaciones y situaciones cuya eventual discusión, además, constituye una auténtica incorrección política. Por otra parte, las constricciones de lo políticamente correcto pueden alcanzar tal altura que el gobierno peruano ha dictado una norma específica sobre el lenguaje inclusivo, lo que no sólo activa la indignación de los custodios de la lengua ${ }^{64}$, sino que supone una carga presupuestaria para la administración y un problema jurídico de cierta altura si se tiene presente que la justificación de motivos alude directamente a la Constitución y al Derecho Internacional ${ }^{65}$. El horizonte en el que un Tribunal Constitucional pueda considerar que la no asunción de este tipo de lenguaje pueda suponer una vulneración del principio de igualdad no parece tan descabezado y lejano.

Y aún restaría, en un nivel diverso, los condicionantes sobre la gestación de la voluntad popular. En la medida en que el tejido social impide una cabal

${ }^{61}$ Para una explicación in extenso de la necesidad de contar con apoyo parlamentario para este tipo de acciones, así como de la evitación intencionada de términos de mayor expresividad bélica, vid. ORTEga SANTIAGO, C., "La dimensión constitucional de la guerra: Conflictos armados e intervenciones militares en el extranjero", en Boletín del Real Instituto Elcano, n. ${ }^{\circ}$ 43, 2004, esp. pp. 27-28.

${ }^{62}$ En 1988 se promulga el Decreto 348/1986 que sustituye los términos "subnormalidad" y "subnormal" de todas las disposiciones reglamentarias por "minusvalía" y "minusválido".

${ }^{63}$ Vid. supra nota 27.

${ }^{64}$ En 2008 aparecía un artículo de prensa que recogía la opinión de Ignacio Bosque, académico de la lengua, para quien "el desdoblamiento es un artificio que distancia aún más el lenguaje de los políticos del lenguaje común". "Ni vascos y vascas, ni diputados y diputadas", en El País, 10/04/2008.

${ }^{65}$ Vid. la Resolución Ministerial n. ${ }^{\circ}$ 052-2009-MIMDES. 
exposición de posiciones que son excluidas ab initio por su supuesta incorrección - no por su inconstitucionalidad- se genera un cuadro socio-político de hipocresía e ideas larvadas y latentes que se aleja bastante del ideal comunicativo habermasiano o del overlapping consensus rawlsiano. Las consecuencias de tal atmósfera no sólo se dejan sentir en forma de debilitamiento democrático, sino que realzan el atractivo ya mencionado de la abierta incorrección política y generan un caldo de cultivo para posiciones reaccionarias que gozan de cierta popularidad por "atreverse" a poner sobre la mesa realidades evitadas por el resto de grupos. Así, por ejemplo, la elisión del fenómeno de la migración en términos de "problemática social" por parte de los políticamente correctos, deja un jugoso espacio político a los partidos de ultra derecha ${ }^{66}$. El ideario progresista y, lo que es más grave, las bases del Estado de derecho, son los que se acaban resintiendo.

Es importante tener presente que las reflexiones vertidas no pretenden pronunciarse sobre las cuestiones materiales de fondo, es decir, no se prejuzga sobre la oportunidad o bondad de las decisiones que puedan adoptarse en las diversas sedes institucionales. Se ha procurado, en cambio, poner de relieve que lo que tiende a presentarse como meros recursos u opciones socio-lingüísticos posee un importante peso político y jurídico. Su ubicación en un plano comunicativo y no directamente normativo tiene como efecto la elisión de la discusión abierta e indisimulada de los posicionamientos sustantivos. Si el conjunto de valores comunes que habilitan la convivencia y justifican el Estado de derecho se halla jurídico-políticamente tasado, las únicas medidas restrictivas legítimas habrían de ser las dispuestas por el propio Estado para la defensa del orden público y los derechos fundamentales. Es por ello que los académicos, los políticos, los juristas y, en otro plano, los ciudadanos, habrían de poner cuidado en adoptar una posición más crítica y activa frente a formas veladas de restricción que permean todo el ordenamiento. Dar la espalda a la imbricación inter-sistémica aquí apuntada desde posiciones formalistas no hace sino exponer a la ciudadanía a lo que, parafraseando a Pérez Luño, puede entenderse como soterrada venganza lingüística del ethos social ${ }^{67}$.

${ }^{66}$ El último ejemplo a este respecto es, paradójicamente, el de Suecia, modelo de Estado social en Europa. Vid. "El rechazo a la inmigración impulsa a la ultraderecha en Suecia. Los radicales entrarán por primera vez en el Parlamento, según los sondeos”, en El País, $18 / 09 / 2010$

${ }^{67}$ Vid. PÉREz LuÑo, A.E., Teoría del derecho. Una concepción de la experiencia jurídica, Tecnos, Madrid, 1997, pp. 108 ss. 


\section{Bibliografía}

Ansuátegui Roig, F. C., Orígenes doctrinales de la libertad de expresión, Universidad Carlos III de Madrid. BOE, Madrid, 1994.

BALLESTER, X., "Indoeuropeo: una lengua para cazadores y recolectrices", Anuario Galego de filoloxia, n. ${ }^{\circ} 33,2006$, pp. 49-68.

CASAS Gómez, M., "El poder mágico de la palabra", Trivium, n. ${ }^{\circ}$ 8, 1996, pp. 29-52.

Casas Gómez, M., "Tabú de palabra e interdicción conceptual”, en A. Pamies Bertrán, A. y Luque Durán, J. De D. (eds.), Trabajos de lexicografía y fraseología contrastivas, Método Ediciones, Granada, 2000.

CATAlá i BAS, A. H., Libertad de expresión e información. La jurisprudencia del TEDH y su recepción por el Tribunal Constitucional, ediciones Revista general de derecho, Valencia, 2001.

Chamizo Domínguez, P. J., "Tabú y lenguaje: las palabras vitandas y la censura lingüística", Thémata. Revista de Filosofía, n. ${ }^{\circ}$ 40, 2008, pp. 31-46.

Cook, J., Tercer Viaje. Diarios de 1776 a 1780, trad. cast. de J. Pomar, José J. de Olañeta ed., Barcelona, 1982..

CREmades, J., Los límites de la libertad de expresión en el ordenamiento jurídico español, La ley-actualidad, Las Rozas, 1995.

DARNTON, R.,"Censorship, a comparative view: France, 1789 - East Germany, 1989", Representations, n. ${ }^{\circ} 49,1995$, pp. 40-60.

Delgado, S., "Poesía guaraní: la antigua búsqueda de la palabra-alma", Revista Electrónica: Documentos Lingüísticos y Literarios UACh, ${ }^{\circ}{ }^{\circ}$ 29, 2006, www.humanidades.uach.cl/documentos_linguisticos/document.php?id=1236

Diccionario de la Real Academia on line: http://buscon.rae.es/draeI/

Domínguez García, V., Tabú: la sombra de lo prohibido, innombrable y contaminante, Ocho y Medio: Festival Internacional de Cine de Gijón: Universidad de Oviedo, 2005.

Douglas, M., Purity and Danger. An analysis of the concepts of pollution and taboo, Routledge and Kegan Paul, London, Boston and Henley, 1980.

Dunant, S. (Ed.), The War of the Words. The Political Correctness Debate, Virago press, London, 1994.

Encyclopaedia Britannica: http://www.britannica.com/eb/article9070845/taboo.

Freud, S., Tótem y tabú, 2. ${ }^{\mathrm{a}}$ ed., trad. cast. de L. López Ballesteros y de Torres, Alianza, Madrid,1968.

GIL, J., La censura en el mundo antiguo, 2. ${ }^{\text {a }}$ ed., Alianza, Madrid, 1985.

Gomis Van Heteren, A., Political correctness in context (The PC Controversy in America), Universidad de Almería, 1997.

Graves, R., "El santo e inefable nombre de Dios", en La Diosa Blanca. Gramática histórica del mito poético, trad. cast. de L. Echávarri, Alianza, Madrid, 1994, pp. 360-399. 
Gubern, R., La censura. Función política y ordenamiento jurídico bajo el franquismo (1936-1975), E. P., Barcelona, 1981.

Guitart Escudero, M. P., Lenguaje político y lenguaje políticamente correcto en España (con especial atención al discurso parlamentario), Tesis doctoral, Universitat de Valencia, Servei de Publicacions, 2005, disponible online en: http://www.tesisenxarxa.net/TDX-0628106$110835 /$

HAAS, M. R., "Interlingual Word Taboos", American Anthropologist, vol. 53, n. ${ }^{\circ}$ 3, 1951, pp. 338-344.

Levine, M. G.,"The subject is Taboo", en $M L N$, vol. 101, n. ${ }^{\circ}$ 5, pp. $977-$ $1002,1986$.

LóPez Morales, H.,"Sociolingüística del tabú”, Interlingüística, n. ${ }^{\circ} 16$, (Ejemplar dedicado a: XX Encuentro de la Asociación de Jóvenes Lingüistas), 2005, www.usal.es/gabinete/comunicacion/conferencia_humberto.pdf.

MalinowsKi, B., La vida sexual de los salvajes del noroeste de Melanesia, 2. ${ }^{\circ}$ ed., trad. cast de R Baeza, Ediciones Morata, Madrid, 1931.

Merriam-Webster Dictionary: http://www.merriam-webster.com/dictionary/ political\%20correctness

Nuevo Diccionario Etimológico Latín- Español y de las voces derivadas, Universidad de Deusto, Bilbao, 2003.

Ortega SANTiago, C., "La dimensión constitucional de la guerra: Conflictos armados e intervenciones militares en el extranjero", Boletín del Real Instituto Elcano, n. ${ }^{\circ}$ 43, 2004

Oxford Latin Dictionary, ed. a cargo de P. G. W. Glare, Clarendon Press, Oxford, 2006.

Pérez LuÑo, A.E., Teoría del derecho. Una concepción de la experiencia jurídica, Tecnos, Madrid, 1997

SÁnCHEZ GONZÁLEZ, S. "Libertad de expresión y democracia", en La libertad de expresión, Marcial Pons, Madrid, 1992, pp. 53-104.

Villanueva, E., Régimen Constitucional de las Libertades de Expresión e Información en los Países del Mundo, fragua editorial, Madrid, 1997.

Webster, H., Le tabou. Étude sociologique, trad. fr. de J. Marty, Payot, Paris, 1952.

WILsON, J. K, The Myth of Political Correctness. The Conservative Attack on Higher Education, Duke University Press, Durham and London, 1995. 